\title{
Direito de Polícia Judiciária: Introdução Às Questões Fundamentais
}

\author{
Eliomar da Silva Pereira ${ }^{1}$
}

\begin{abstract}
RESUMO
O Direito de Polícia Judiciária concerne ao direito de organização e de procedimento com que a Polícia Judiciária exerce suas funções nas relações com os demais órgãos do poder punitivo no processo penal, tendo em vista uma efetiva garantia dos direitos fundamentais no processo penal. Ele se pode referir tanto ao estudo do regime jurídico constitucional, administrativo e processual de uma Polícia Judiciária nacional em específico (perspectiva dogmática), quanto se pode referir a uma ideia mais geral de Polícia Judiciária que interessa a todos os sistemas processuais penais, naquilo que diz respeito ao seu funcionamento em conformidade com postulados fundamentais de um Estado de Direito, notadamente a divisão do poder punitivo e a proporcionalidade processual (perspectiva zetética). Esse artigo se destina a discutir a possibilidade de um específico direito de polícia judiciária, no quadro de um direito de polícia geral, bem como a ideia de polícia judiciária como instituição (órgão e função) necessária à realização de um devido processo penal.
\end{abstract}

PALAVRAS-CHAVE: Polícia; Polícia Judiciária; Direito; Direito de polícia; Direito de polícia judiciária; Estado de direito; Divisão de poder; Direitos fundamentais; Proporcionalidade; Devido processo penal.

SUMÁRIO: I. O direito de polícia judiciária. II. A "ideia geral" de polícia judiciária. 2.1. A construção histórica da polícia judiciária. 2.2. A polícia judiciária no "Code d'Instruction Criminelle". 2.3. A concepção

1 Doutorando em Direito (Escola de Lisboa-Universidade Católica Portuguesa), Mestre em Ciências Policiais (Instituto Superior de Ciências Policiais e Segurança Interna Portugal), reconhecido como equivalente a Mestrado em Direito (Universidade de Brasília), Especialista em Ciências Criminais (Unama), Professor da Escola Superior de Polícia (Polícia Federal do Brasil), Delegado de Polícia Federal (Brasília-DF). 
de Faustin Helie. III. A polícia judiciária no Brasil. 3.1. A legislação processual penal. 3.2. A polícia judiciária na Constituição. 3.3. As concepções doutrinárias. IV. Considerações finais. 4.1. Polícia judiciária, função e órgão. 4.2. Direito de polícia judiciária, zetética e dogmática. Referências bibliográficas.

\section{O Direito de Polícia Judiciária}

1. O direito de polícia em geral não tem merecido a devida atenção da ciência jurídica, embora se possam encontrar alguns tratados, nos quais ainda o direito de polícia judiciária é quase absolutamente ignorado. Luigi Ferrajoli, ao tratar do subsistema penal de polícia dentro do sistema jurídico-penal, adverte-nos que:

O direito de polícia, porque direito inferior, ou pior, não direito, representa, talvez, o setor mais negligenciado dos estudos acadêmicos. Manifesta-se, todavia, nesta matéria, uma espécie de esquizofrenia da ciência jurídica: tão atenta aos limites entre direito penal e administrativo, com respeito às contravenções e aos outros delitos de bagatela e, até mesmo, virtuosamente preocupada com as possíveis diminuições de garantais que se seguem à despenalização, quanto desatenta ou não responsabilizada com respeito ao grande universo das medidas policialescas e administrativa restritivas de liberdade pessoal. ${ }^{2}$

Miguel Pizarro, nesse mesmo sentido, também observa que o estudo das questões jurídicas atinentes à polícia foi, por muito tempo, lamentavelmente subestimado, não se tendo percebido a polícia como uma das mais importantes manifestações do direito público moderno. Mas, com essas considerações, o autor pretende reabilitar o estudo da polícia, não mais como capítulo incidental do Direito administrativo, mas sim como ramo autônomo da Ciência jurídica, com princípios próprios e problemas bem específicos ${ }^{3}$.

2 FERRAJOLI, L. Direito e Razão, 2002, p. 616.

3 LLERAS PIZARRO, M. Derecho de Policía, 2009, p. 19 ss. 
As razões que existem na base dessa "negligência intelectual" - deve-se admitir - não são originariamente jurídicas, mas políticas e sociológicas. Elas, contudo, decorrem em grande medida da natureza de seu objeto ou, mais especificamente, dos sujeitos com que o direito de polícia lida. Ferrajoli considera que três razões são fundamentais à compreensão dessa negligência.

Existe, primeiro, uma estranha hierarquia nobiliárquica entre os ramos de estudos jurídicos que vem desde o direito romano, no qual se punha acima de todos o direito civil, ao qual se seguia o direito público em geral e o penal por fim, para somente então se tratar do direito de polícia em sua praxe. Há, nessa razão, uma contradição, pois quanto mais se torna difícil justificar a legitimação do direito, mais parece haver menor empenho em seu estudo e reflexão. Essa primeira razão nos remete a outra que consiste no fato de o direito de polícia encontrar uma maior dificuldade de estruturar-se segundo as formas constitucionais do Estado de direito - em conformidade com a divisão do poder e inviolabilidade dos direitos fundamentais - e suas doutrinas liberais e democráticas que se encontram nos fundamentos do Estado moderno, expondo a inefetividade prática do seu arcabouço teórico. A preterição ao direito de polícia que dessas razões decorre - embora não seja consciente e deliberada - ao final implica em uma espécie de "tratamento de classe" que a cultura jurídica acaba por assimilar. Porque as medidas de polícia, sobretudo as de prevenção, estão orientadas a uma classe mais marginalizada, também o direito que lhe corresponde resulta marginalizado dos estudos da ciência jurídica ${ }^{4}$.

2. Não é, portanto, de estranhar-se que o direito de polícia judiciária, com maior razão ainda, também se tenha deixado de lado de discussão jurídica mais detida, não apenas no Brasil, mas igualmente em vários outros países. Associado a uma fun-

4 FERRAJOLI, L. Direito e Razão, 2002, p. 617ss. 
ção estatal que dificilmente alcançava classes proeminentes da sociedade, a investigação criminal que se desenvolve no inquérito policial sempre esteve reduzida a "mera peça de informação" que "não gera qualquer nulidade no processo", sem maiores discussões jurídicas sobre sua competência, limites e efeitos ${ }^{5}$. Essa é a principal linha de interpretação contida na doutrina processual penal brasileira que, por décadas, dominou as faculdades e ainda tem orientado cursos preparatórios de concursos jurídicos em todo o país.

O direito de polícia judiciária é, nesse sentido, absolutamente negligenciado, com raríssimas exceções que se podem encontrar em alguns tratados gerais. Mas aquilo que Luigi Ferrajoli vem a chamar de "direito processual de polícia"6, que concerne ao âmbito de "atos de polícia judiciária" relativos à função da polícia judiciária no processo penal, contudo, pressupõe uma compreensão constitucional da organização da polícia judiciária que muito dificilmente se consegue encontrar nas obras de direito de polícia em geral.

As poucas obras que se encontram sobre o direito de polícia em geral, especialmente estrangeiras, com algumas poucas ressalvas, quase não conseguem identificar o que há de especialmente relevante no ramo de um direito de polícia judiciária, limitando a tratar da polícia administrativa e de seus diversos ramos possíveis de aplicação ${ }^{7}$ Muitas não levam a sério a questão fundamental que é posta pela legislação francesa pós-revolucionária ao postular a divisão da polícia em administrativa e judiciária, como uma continuidade da ideia geral de divisão do poder. Essa,

5 Nesse sentido, por todos que ainda o seguem, cf. TOURINHO FILHO, F. C. Processo Penal, V. 1. 2002, p. 177ss.

6 FERRAJOLI, L. Direito e Razão, 2002, pl. 634ss.

7 A exemplo de GOENAGA, M. Lecciones de derecho de policía, Bogotá: Temis, 1983; SALAZAR CULI, F. Derecho de Policía. Polícia administrativa. Barcelona-Buenos Aires: Salvat Editores, 1942. 
contudo, nos parece ser a principal linha de interpretação com que devemos perscrutar a questão fundamental do direito de polícia judiciária, que vem na doutrina processual penal brasileira bem compreendida por Hélio Tornaghi, para quem "a divisão dos poderes ocorreu para demarcar os campos da justiça e da polícia, e dentro desta, permitiu distinguir a administrativa da judiciária"8.

3. Giuseppe Tamburro, embora muito comedidamente, observa que, sendo o nascimento da Polícia correlativo ao nascimento do Estado, o seu direito deveria igualmente seguir-se ao direito do Estado, segundo as suas diretrizes de disciplina dos direitos de liberdade do indivíduo. Em seu estudo sobre o direito de polícia na época fascista, encontram-se tentativas de distinguir a polícia segurança da polícia judiciária, a partir da distinção entre administração e jurisdição, entre ordenamento jurídico de polícia e ordenamento jurídico penal. Mas, conquanto tente falar da polícia judiciária, o autor parece empurrar a disciplina de seus atos para outro ramo jurídico que não o direito de polícia, deixando-o entregue ao direito do processo penal, no qual, contudo, o direito de polícia judiciária acaba não alcançando sua devida atenção necessária, embora na prática disponha de tantos direitos fundamentais 9 .

Essa disciplina contida no âmbito do processo penal parece igualmente se ter replicado na cultura jurídica brasileira que apenas trata da polícia judiciária como capítulo restrito do direito processual, limitando-se ainda a um subtítulo anterior ao que lhe interessa mais diretamente $-\mathrm{o}$ inquérito policial ${ }^{10}$. Com isso, perde-se de vista algumas questões constitucionais que concer-

8 TORNAGHI, H. Instituições de Processo Penal, V. 2, 1977, p. 200.

9 TAMBURRO, G. Il diritto di polizia. La polizia amministrativa e la polizia di sicurezza nella legislazione fascista, 1938, p. 52ss.

10 Nesse sentido, cf. MARQUES, J. F. Elementos de Direito Processual Penal, V. I, 2000, p. 158 ss. 
nem não apenas à função de polícia, mas ao órgão que se encarna nos corpos de polícias que a assumem como atribuição própria.

Não bastasse isso, ademais, perde-se de vista sobretudo questões que concernem aos direitos fundamentais implicados no desenvolvimento da função de polícia judiciária, que embora abranjam um enorme âmbito de direitos, tendem a ter na disciplina processual penal um espaço tão diminuto que não corresponde à seriedade das restrições realizadas pela prática de polícia judiciária. A esse respeito, manuais mais tradicionais de processo penal - na continuidade da ideia do inquérito policial como "mera peça de informação que não gera nulidades à ação penal", continham ínfimas páginas dedicadas à função da polícia judiciária ${ }^{11}$.

4. Miguel Lleras Pizarro, por sua vez, embora enfrente o tema da polícia judiciária mais expressamente, deixa-a deliberadamente de fora de seu Derecho de Policía, embora tenha uma perspectiva metodológica da disciplina- organizado em torno dos direitos e liberdades fundamentais em relação com a atividade policial - que poderia incluir a polícia judiciária em sua compreensão.

Miguel Pizarro principia com uma distinção entre regime de fato, regime de direito e regime de polícia. Trata-se de distinção formulada por tratadistas de Direito público. No regime de fato, prevalece a lei do mais forte. No regime de direito, prevalece a lei de garantia de direitos, estando os cidadãos apenas submetidos às sanções por violação das normas. É somente no regime de polícia que se admitem limitações preventivas dos direitos. Contudo, observa o autor muito atentamente que o regime de polícia é uma consequência do direito, já que sua existência não pode conceber-se independentemente, nem se pode imaginar uma or-

11 Nesse sentido, cf. p. ex. CAPEZ, F. Curso de processo penal, 2002, embora se deva admitir que manuais mais atuais têm dado uma melhor atenção a esse capítulo, mas ainda sem enfrentar a questão da polícia judiciária como órgão mais seriamente. 
ganização social submetida exclusivamente ao regime de polícia, pois a prevenção é uma situação excepcional, que se justifica por razões de convivência social orientada a facilitar a mais perfeita realização do direito. $\mathrm{O}$ autor tem, assim, em vista a função preventiva da polícia. É um direito de polícia voltado essencialmente à polícia de segurança pública ${ }^{12}$.

Para Miguel Pizarro há um equívoco em falar de polícia com função repressiva, como atividade desenvolvida após a comissão de um delito, orientada a buscar, capturar e conduzir aos tribunais os supostos responsáveis. Estas operações de colaboração na repressão penal não são características da polícia, nem lhe são próprias ${ }^{13}$. A ideia de uma polícia judiciária, portanto, decorre do fato de que tais operações são desempenhadas na Colômbia pelo mesmo corpo de polícia, em função de órgão judiciário; trata-se, em suma, de funções judiciais - é o que entende Pizarro, e temos que lhe conferir razão, embora devamos ponderar algumas questões.

5. Manuel Monteiro Guedes Valente, em sentido inverso, sustenta uma Teoria Geral do Direito Policial que pretende abranger atos que concernem à atividade de polícia judiciária, incluindo expressamente capítulo sobre a investigação criminal ${ }^{14}$. A concepção teórica do autor se deve compreender no quadro do regime jurídico da investigação criminal em Portugal, onde todas as polícias são chamadas a participar da função de polícia judiciária sob o título de "órgãos de polícia criminal" entre os quais se encontram não apenas a polícia judiciária e a polícia de segurança, mas outros tantos órgãos administrativos que estão autorizados a exercer essa função de apoio ao processo penal, segundo uma distinção de competências genéricas e específicas ${ }^{15}$.

12 LLERAS PIZARRO, M. Derecho de Policía, 2009, p. 33ss.

13 LLERAS PIZARRO, M. Derecho de Policía, 2009, p. 37ss.

14 GUEDES VALENTE, M. M. Teoria Geral do Direito Policial, 2014.

15 GUEDES VALENTE, M. M. Teoria Geral do Direito Policial, 2014, p. 439ss. 
Manuel Valente considera que os órgãos de polícia criminal, cujo sentido se remete à polícia judiciária, "se distingue da polícia em sentido administrativo pela própria natureza das medidas que aplica em uma e em outras circunstâncias congregadoras". Por estarem as polícias portuguesas em função administrativa da justiça penal na dependência da autoridade judiciária, é, portanto, "por meio desta coadjuvação que a polícia judiciária ou criminal desenvolve a função"16.

Nesse quadro jurídico, portanto, em que a função de polícia judiciária é exercida na dependência de uma autoridade judiciária, não como função autônoma da polícia, é acertado tratar do direito de polícia judiciária como capítulo do direito geral de polícia, não havendo razão para deixá-lo de fora como o pretendia Miguel Lleras Pizarro, embora tenha admitido o mesmo princípio orientador que Manuel Monteiro Guedes Valente.

6. Certo é que, mesmo nessa linha de compreensão da função de polícia judiciária como competência que se exerce na dependência da autoridade judiciária, como acontece igualmente em Itália, podemos encontrar disciplina específica sobre "direito de polícia judiciária", destacada do direito de polícia geral, mas já aqui como uma questão de autonomia metodológica da disciplina, sem correspondência com uma teoria autônoma da polícia judiciária.

Vitor Ingletti, por exemplo, nesse sentido, dispõe em seu Diritto de polizia giudiziaria de toda a disciplina que concerne à atividade da polícia judiciária no âmbito do processo penal, mas o faz de uma perspectiva limitada que nada agrega cientificamente à construção de uma disciplina jurídica específica. Ele apenas trata dos atos que concernem a essa atividade, apresentando toda a disciplina jurídica - penal e processual penal - que concorre

16 GUEDES VAlENTE, M. M. Teoria Geral do Direito Policial, 2014, p. 70. 
ao direito de polícia, mas nada acrescendo que a constitua como disciplina autônoma ${ }^{17}$. Em suma, diversamente de Manuel M. G. Valente, o autor italiano se limita a compilar todo o direito que se pode exigir na atividade de polícia judiciária que se exerce por órgãos gerais de polícia, o que efetivamente em nada concorre à construção científica da disciplina autonomamente.

7. Em todo caso, contudo, o direito de polícia judiciária subsiste como um campo disciplinar da ciência jurídica, quer como capítulo de um direito geral de polícia, quer como disciplina autônoma, mas a depender do modelo de polícia que se tem, tendo em conta questões relativas a (i) unificação ou diversificação de funções e órgãos; (ii) sua competência exclusiva ou concorrente para as funções de investigação; (iii) sua relativa ou absoluta autonomia quanto aos demais órgãos estatais; (iv) forma de controles interno e externos de sua organização e funcionamento; e sobretudo (v) questão dos limites de sua atividade, com respeito a restrições aos direitos fundamentais.

Não se pode, nesse sentido, pelo menos a princípio, esperar que o direito de um determinado país tenha em conta as particularidades de uma polícia judiciária no quadro geral de um direito de polícia, sem levar em conta o modelo de polícia nacional. Mas há algo que parece transcender a nacionalidade das questões pontuais e exigir uma compreensão anterior da ideia geral de polícia, embora essa noção de "ideia geral" se tenha suscitado pela doutrina francesa no quadro de sua história das instituições processuais penais, que não se deve assumir sem maiores considerações

A possibilidade de um direito de polícia judiciária está, portanto, a depender de que possamos compreender questões jurídicas específicas que exsurgem desse âmbito de problemas e

17 INGLETTI, V. Diritto di polizia giudiziaria, 2015. 
os princípios gerais que lhe devemos aplicar. E nossa hipótese é que, a título de proposta, tentemos reconstituir as razões que levaram à criação de uma polícia judiciária, a partir da experiência histórica francesa.

\section{A “Ideia Geral" de Polícia Judiciária}

8. A “ideia geral de polícia judiciária"18 e o direito que lhe corresponde são compreensíveis apenas no quadro das relações entre regime político e sistema processual, cujo momento culminante se pode encontrar na Revolução Francesa e se vai consolidar no Code d'Instruction Criminelle (CIC) de 1808. Muitas mudanças sobrevieram ao processo penal nos séculos XIX e XX, mas aquela ideia permanece mesmo no século $X X I$, e talvez somente agora em condições de ser melhor compreendida.

É até possível perscrutar no passado do processo penal do Ancien Regímen funções que se vão assumir pela polícia judiciária na legislação processual pós-revolucionária, mas dificilmente se pode captar o espírito novo dessa instituição sem compreender a lógica constitucionalista da Declaration des Droits de l'Homme et du Citoyen de 1789, sintetizada em seu artigo 16: "Toute Société dans laquelle la garantie des Droits n'est pas assurée, ni la séparation des Pouvoirs déterminée, n'a point de Constitution".

A polícia judiciária é, nesse sentido, filha da Revolução Francesa, partilha de seus ideais fundamentais, de suas oscilações vindouras e persiste, portanto, como um ideal irrealizado ${ }^{19}$. Ela é, pois, a continuidade persistente do espírito incompreen-

18 Título com que FAUTIN HELIE, M. Traite de l'instruction criminelle, 1866, p. 3, inicia o Livre Trosième dedicado à Police Judiciaire.

19 PARKER, N. As revoluções e a história, 2001, p. 13ss: A Revolução Francesa, como outras grandes revoluções, constitui mais tentativas de mudança que mudanças reais, algumas é certo frustradas, outras destinadas a permanecer vivas ainda que não realizadas em sua totalidade. 
dido de uma ideia revolucionária no processo penal que não se realizou ou que se realizou no CIC de 1808 em sentido diverso do que se postulava originariamente pela legislação imediatamente pós-revolucionária.

O direito de polícia judiciária, que se pensa possível, é, antes e acima de tudo, uma teoria interpretativa dessa instituição, na história do pensamento constitucional e processual penal, para que possamos avançar depois com uma concepção possível no sistema jurídico brasileiro.

\subsection{A CONSTRUÇÃo HISTÓRICA DA POLÍCIA JUDICIÁRIA}

9. Podem-se encontrar funções de polícia judiciária em tempos mais distantes - como os curiosi na Roma Antiga ou os pesquisadores no antigo direito ibérico ${ }^{20}-$, mas as razões histórico-políticas que nos permitem compreender sua ideia se encontram mesmo na legislação processual penal da França pós-revolucionária. Contudo, para que se compreenda a intuição fundamental dessa legislação, é preciso recorrer ao estado de coisas no antigo regime do processo penal.

É que no sistema inquisitório medieval, o juiz cometia as suas funções de polícia judiciária a um oficial inferior que deveria limitar-se a seguir ordens, mas que acabava extrapolando a comissão. A Ordonnance de 1670 até tentou impedir que esse comissário exercesse direito e autoridade de juiz, mas na prática esse limite não era observado. Nessa época, portanto, o que será um dia a "polícia judiciária" tinha por agentes todos os juízes. Nesse contexto, administração e justiça estão confundidas, por-

20 TUCCI, R. L. Lineamentos de processo penal romano, 1976, p. 173; SANTALUCIA, B. Diritto e processo penale nell' antica Roma, 1998, 189ss; ALESSI, G. Il processo penale. Profilo storico, 2011, p. 54ss; MINGUIJÓN ADRIÁN, S. Historia del derecho español I, 1927, p. 200. 
que havia juízes com funções administrativas e órgãos de administração com funções judiciárias ${ }^{21}$.

A primeira tentativa de fazer uma separação séria entre polícia e justiça vem com a criação do "lieutenant" general de polícia, por um Edito de 1667, que constituía o protótipo antigo da polícia administrativa ${ }^{22}$. É, contudo, no desenvolvimento da Revolução Francesa que a polícia judiciária vai encontrar suas razões e buscar uma separação da administração.

Mas na primeira fase da Revolução, período marcado pela desconfiança na magistratura, dominada pela Assembleia Nacional ${ }^{23}$, o corpo judiciário ficará dependente do poder administrativo local ou do legislativo. E nesse contexto, a polícia judiciária ainda não se distingue da administrativa. A polícia de sûreté compreende funções de investigação, acusação e instrução, todas acumuladas no juiz de paz ${ }^{24}$.

No período revolucionário conhecido como "fase do Terror", centraliza-se o poder na Convenção, na forma de uma democracia totalitária, em que prevalecia a tese de Rousseau da soberania popular sobre a tese de Montesquieu da separação do poder. Nesse período, subtrai-se toda função de polícia da magistratura, havendo uma prevalência de funções administrativas com medidas de caráter preventivo ${ }^{25}$.

21 TONINI, P. Polizia giudiziaria e magistratura, 1979, p. 14ss.FAUSTIN HELIE, M. Traite de l'instruction criminelle, 1866, p. 18ss.

22 TONINI, P. Polizia giudiziaria e magistratura, 1979, p. 18ss.

23 É preciso ter em mente que, durante a Revolução Francesa (1789-1799), contêm-se quatro períodos marcados pela Assembleia Constituinte (1789-1791), a Assembleia Legislativa (1791-192), a Convenção (1792-1795), dividido por contradições entre a República Jacobina e a República Termidoriana, e o Diretório (1795-1799). (VOVELLE, M. A Revolução Francesa (1789-1799), 2007).

24 TONINI, P. Polizia giudiziaria e magistratura, 1979, p. 31ss.

25 TONINI, P. Polizia giudiziaria e magistratura, 1979, p. 47ss. 
Na fase da Revolução dominada pelo Diretório, há uma tentativa de retorno aos princípios de 1791 (Assembleia Constitucional), com alguma limitação do poder legislativo. É nesse contexto que surge o Código dos Delitos e das Penas de 3 Brumário do Ano IV (25 de outubro de 1795) ${ }^{26}$, obra de Merlin de Douai, votado em bloco e sem discussão na Convenção Termidoriana ${ }^{27}$, que distingue a polícia administrativa da judiciária. A separação é feita em razão dos abusos anteriores da fase do Terror, quando ser suspeito constituía uma infração que permitia a limitação da liberdade ${ }^{28}$. Nesse contexto, surge a distinção clássica, que marca o nascimento formal da polícia judiciária no ocidente, que virá depois assumida pelo Code d'Instruction Criminelle de 1808: "A polícia é instituída para manter a ordem e a tranquilidade pública, a liberdade, a propriedade, a segurança individual [...]. A polícia administrativa tem por objeto a manutenção habitual da ordem pública em cada local e em cada parte da administração geral. Seu objetivo principal é prevenir os delitos. Ela manda executar as leis, ordenações, regulamentos de ordem pública. [...] A polícia judiciária investiga os crimes, os delitos e as contravenções que a polícia administrativa não conseguiu impedir de cometer, reúne provas e entrega os autores aos tribunais encarregados de puni-los" 29 .

Na organização, os oficiais de polícia judiciária estavam imediatamente sob vigilância do diretor do Júri, que era um órgão popular, e apenas indiretamente sob vigilância da acusação

26 Os anos do Calendário Revolucionário (que durou apenas até 1805, quando Bonaparte restabelece o Calendário Gregoriano) contam-se a partir da Convenção Internacional de 1792 e os meses (vindemiário, brumário, frimário etc.), com início no outono, começam no dia 22 de setembro, tendo cada mês 30 dias, sendo os cinco último (de 17 a 21 de setembro) dias feriados dos sans-culottes.

27 Aos termidorianos se deve a Constituição de 1975 (Constituição do ANO III), que instala o Diretório, após a queda de Robespierre, e se aplica até 1799, quando se instala o Consulado.

28 TONINI, P. Polizia giudiziaria e magistratura, 1979, p. 60ss.

29 FAUTIN HELIE, M. Traite de l'instruction criminelle, 1866, p. 5 ss. 
pública. Nesse contexto, contudo, dizia-se que faltava um órgão que assumisse a iniciativa material do processo, o que demonstrou, segundo os historiadores, uma insuficiência na repressão aos crimes $^{30}$.

Apesar das críticas ao regime do Diretório, os historiadores admitem que nela se pôs fim à instabilidade e anarquia, permitindo uma nova Constituição em 1797 com a qual o poder executivo se fortalece nas mãos do cônsul e se instala a fase do Consulado. Contudo, o país ainda está com alto índice de criminalidade e a Lei de 7 Puvioso do Ano IX vem para enfrentar essa questão, aumentando as funções da acusação pública na fase de instrução. O Ministério Público, nessa fase, aumentara seus poderes até ao ponto de exercer atos de tipo jurisdicional. Como observam os historiadores, o Consulado foi uma instituição de governo francês entre a queda dos diretórios (18 Brumário de 1799) e o começo do Império de Napoleão em 1804, mas é já marcado por diretrizes napoleônicas, embora exercido por três cônsules. "Com este golpe de Estado sem grandeza conclui-se a história da Revolução Francesa. Começa então a aventura napoleônica"31. Essa nova fase será marcada pelo protótipo de código processual penal europeu-continental que por muito tempo influenciou o processo penal do ocidente.

\subsection{A POLÍCIA JUdiciáRIA NO “CODE D'INSTRUCTION CRIMINEL- $L E^{\prime \prime}$}

10. O CIC de 1808, conquanto tenha mantido a polícia judiciária, tendo distinguido entre polícia judiciária e instrução, bem como entre essa e acusação, coloca a polícia judiciária sob a dependência funcional do Ministério Público. É a representação do caráter

30 TONINI, P. Polizia giudiziaria e magistratura, 1979, p. 62ss; FAUTIN HELIE, M. Traite de l'instruction criminelle, 1866, p. 66ss.

31 VOVELLE, M. A Revolução Francesa: 1789-1799, 2007, p. 65. 
totalitário do regime político napoleônico que se transmite ao sistema processual sob uma divisão meramente formal do poder. O CIC, na fase preliminar do processo, era em síntese um retorno ao Antigo Regime processual da Ordonnance de $1670^{32}$.

Nesse Código, as funções de polícia judiciária e de acusação vêm concentradas nas mãos do procurador, excluindo o direito de defesa na fase de instrução. E embora o juiz pudesse investigar e assumir de ofício a prova, sua instrução somente se iniciava e terminava a pedido do Ministério Público ${ }^{33}$. Nesse sistema, toda a matéria do juiz instrutor vinha referida como questão de polícia judiciária. E o próprio Ministério Público se assume como um agente de polícia judiciária, entre os quais também se vai encontrar o juiz de instrução e outros.

A polícia judiciária é considerada no CIC uma função essencial ao exercício da justiça. Todo o Livro 1 do CIC contem disposições sobre quem a exerce e como se desenvolvem os atos necessários ao exercício da justiça que se encontram disciplinados no Livro 2. Admite-se, nesse sentido, no sistema do CIC, que a função do Estado de fazer justiça exige operações de ordem administrativa e de ordem jurisdicional ${ }^{34}$. A polícia judiciária se exerce por vários agentes, entre os quais, como oficiais superiores, se encontram o procurador da República e o juiz de instrução, auxiliados por outros oficiais. Entre os oficiais auxiliares do procurador da República, encontram-se juízes de paz e comissários de polícia. O procurador da República, portanto, reúne no sistema do CIC as qualidades de oficial de polícia judiciaria e de membro do Ministério Público, assim como o juiz de instrutor, além de magistrado de instrução, é também oficial de polícia judiciária ${ }^{35}$.

32 ESMEIN, A. Histoire de la procédure criminelle em France et spécialement de la procédure inquisitoire depuis le XIIIe siècle jusqu'a nos jours, 1969, p. 532.

33 TONINI, P. Polizia giudiziaria e magistratura, 1979, p. 89ss.

34 GARRAUD, R. Compendio de direito criminal, 1915, p. 176.

35 GARRAUD, R. Compendio de direito criminal, 1915, p. 224ss. 
A instrução preparatória está marcada por três caracteres. $1^{\circ}$ ) A instrução é não contraditória. Desenvolve-se segundo um jogo de força entre um magistrado e o acusado. Enquanto o Ministério Público pode, a todo momento, tomar conhecimento das peças do processo, o acusado se encontra afastado. $O$ único direito que tinha era fornecer à câmara de acusação seus memoriais sobre acusações que ignorava. $2^{\underline{o}}$ ) A instrução é secreta. Toda ela se desenvolve no gabinete do magistrado instrutor com seu escrivão. $3^{\circ}$ ) A instrução é escrita. E é sobre esse processo escrito que se decide a instrução.

A instrução preparatória se desenvolve por dois magistrados, o procurador da República que requer e o juiz de instrução que ordena as medidas necessárias à descoberta da verdade. O juiz de instrução não deve começar nem terminar a instrução sem requerimento escrito do procurador da República. Nesse sentido é que se fala de separação de poderes de instrução e de investigação entre magistrados no sistema do $\mathrm{CIC}^{36}$. Diz-se que, nessa posição, o juiz de instrução era um oficial de polícia judiciária, que ficava limitado a instruir in rem, nunca in persona. $\mathrm{O}$ procurador da República tem o direito de fiscalizar a instrução, requerendo a comunicação do dossier, para fazer requisições, embora o juiz pudesse repeli-las, sem prejuízo de sofrer também oposição pelo procurador.

Os atos principais da instrução são a procura das infrações e seu autor. Entre os meios de investigação e de provas encontram-se a inspeção pessoal do juiz por visita a lugares, domicílio e apreensões necessárias, bem como a oitiva de testemunhas e interrogatório do investigado, além de exames. Todos se fazem sem contraditório. E a oitiva das testemunhas, que é a atividade fundamental, ao que se chama de informação, faz-se secretamen$t^{37}$. Essas atividades, contudo, se realizavam efetivamente por

36 GARRAUD, R. Compendio de direito criminal, 1915, p. 242ss.

37 GARRAUD, R. Compendio de direito criminal, 1915, p. 275ss. 
delegação (obrigatória) a oficiais de polícia judiciária sempre que se deviam realizar em distrito distinto de onde não se encontrava o juiz ou o procurador, sendo possíveis (facultativa) mesmo nos distritos onde se encontrassem ${ }^{38}$. Esse é o modelo que se vai reproduzir essencialmente por grandes codificações do século XIX e, com algumas variações, chega até os séculos XX e XXI.

\subsection{A CONCEPÇÃO DE FAUSTIN HELIE}

11. A “ideia geral de polícia judiciária” que M. Fautin Helie nos traz, portanto, pressupõe a história francesa e a disciplina normativa do CIC, a partir do qual precisamos ter em conta questões outras. É, portanto, não uma ideia geral, para todos os tempos e espaços jurídicos, mas uma ideia francesa, a partir da qual precisa seguir a história. Nesse contexto, a polícia judiciária é ainda uma atividade, uma função essencial à justiça, não necessariamente um órgão específico da estrutura do Estado. Ela se encontra distribuída entre diversos órgãos que não são originariamente polícias judiciárias, mas polícias administrativas ou até mesmo juízes e procuradores.

Daí o conceito inicial com que o autor a define: "A polícia judiciária é, em geral, um tipo de instrução preparatória que precede a instrução feita pelo juiz" ${ }^{39}$. Ela se compreende, nesse sentido, como uma atividade delimitada temporalmente, que começa quando o crime ocorre e termina com a propositura da ação. E disso resulta sua missão que consiste em "relatar crimes e delitos, logo que são cometidos, em receber denúncias, em pegar sumariamente, em caso de flagrante, os indícios e as provas de sua perpetração e em transmitir imediatamente à autoridade judiciária os atos desse inquérito preliminar".

38 GARRAUD, R. Compendio de direito criminal, 1915, p. 288ss.

39 FAUTIN HELIE, M. Traite de l'instruction criminelle, 1866, p. 5ss. 
Fautin Helie considera que dessa sua definição (delimitação e missão), é possível extrair as características com as quais podemos pensar os princípios que devem dominar a organização da polícia judiciária. Inicialmente, por um lado, a polícia judiciária prepara a ação do juiz, pois ao precedê-lo, facilita a instrução, sendo, portanto, uma atividade provisória que pesquisa, constata, pergunta, mas não aprecia nem age. De outra parte, embora não participe da ação judiciária propriamente dita, a polícia judiciaria emana da justiça, pois recebe uma delegação temporária, agindo em seu nome e no seu interesse ${ }^{40}$.

A ideia de polícia judiciária, nesse sentido, exige princípios que devem orientar a sua organização. Primeiro, ela precisa ser investida dos meios necessários à realização de sua missão, mas, em segundo, em razão dos direitos que ela pode ofender, suas ações devem ser cercadas de formas tutelares que a aproxime, o máximo possível, das formas judiciárias. É o que conclui Fautin Helie. Nessa sua concepção, “é necessário que ela seja investida de um certo poder e que ela possa empregar alguns meios de verificação e de ação que pertencem, em geral, ao poder judiciário", mas sempre como atividade preparatória do processo judiciário, e enquanto pendente sua intervenção. Mas, precisamente por isso, "ela deve apresentar em seus atos algumas garantias judiciárias". Nesse ponto, o autor exige pontualmente condições especiais aos seus agentes, bem como que suas competências sejam regulamentadas com atribuições muito bem definidas. E, em especial, que os efeitos de seus atos e sua influência nas decisões da justiça sejam medidos "segundo a natureza dos fatos e a autoridade da qual os agentes são investidos"41.

Essa, contudo, é uma ideia geral de Polícia Judiciária que Faustin Helie tem no contexto do CIC 1808, tendo em conta a

40 FAUTIN HELIE, M. Traite de l'instruction criminelle, 1866, p. 7ss.

41 FAUTIN HELIE, M. Traite de l'instruction criminelle, 1866, p. 8. 
história que se conduz até ele. É um ponto de partida - não conclusivo ao nosso tempo, tampouco ao espaço do direito brasileiro - pois requer ser compreendido em suas razões e atualizadas.

\section{A Polícia Judiciária no Brasil}

\subsection{A LEGISLAÇÃO PROCESSUAL PENAL}

12. A história das instituições processuais penais no Brasil também se pode compreender segundo o princípio de distinção entre judiciário e polícia. A primeira tentativa se encontra no Alvará de 25 de junho de 1760 que, ao criar o lugar de Intendente Geral de Polícia, manifestando o objetivo de separar as funções de juízes criminais acumulando funções policiais, acaba por concentrar no Intendente funções judiciárias ${ }^{42}$.

Essa confusão persiste com a Lei de 13 de outubro de 1827 que cria os juizados de paz em cada freguesia do Império, nos quais se concentram atribuições policiais, tanto preventivas quanto repressivas, bem como funções informativas e probatórias, situação que se mantém até o Código de Processo Criminal de 1832, no qual se estabelece a competência de "inspetores de quarteirão" com atribuições de prevenção dos crimes e prisão de criminosos em flagrante.

É apenas com a Lei n. 261 de 1841 - considerada uma das mais importantes leis da história política do Império $^{43}$ - que se estabelece a função de "chefe de polícia", escolhidos dentre desembargadores e juízes de direito, aos quais se subordinavam como autoridades policiais os delegados e subdelegados, escolhidos entre quaisquer juízes e cidadãos. Mas essa Lei não fazia distinção expressa entre polícia administrativa e polícia judiciária, tampouco falava em inquérito ou investigação.

42 MENDES DE ALMEIDA, J. C. Princípios fundamentais do processo penal, 1973, p. 62.

43 Nesse sentido, cf. TORNAGHI, H. Instituições de processo penal II, 1977, p. 217. 
O Regulamento no 120 de 1842, "para execução da parte polícia e criminal" da Lei 261, é que vai distinguir expressamente polícia administrativa e polícia judiciária, ao estabelecer em seu art. $3^{\underline{0}}$ que: "São de competência da polícia judiciária: $1^{\mathrm{o}} \mathrm{A}$ atribuição de proceder a corpo de delito, compreendida no $\S 4^{\underline{0}}$ do art. 12 do Código de Processo Penal; 2ํㅡ A de prender os culpados, compreendida no §5ำ do mesmo artigo do dito Código; $3^{\underline{0}}$ A de conceder mandados de busca; $4^{\underline{0}}$ A de julgar os crimes a que não esteja imposta pena maior que multa até cem mil-réis, prisão, degredo, ou desterro até seis meses, com multa correspondente à metade desse tempo, ou sem ela e três meses de Casa de Correção ou oficinas públicas, onde as houver".

A reforma da organização judiciária que vem com a Lei no 22.003 de 1871 não contém nenhuma disposição relativa à polícia, embora se encontrem algumas que extinguem a jurisdição das autoridades policiais, ressalvadas ao chefe de polícia a faculdade de proceder à formação da culpa no caso do art. 60 do Regulamento 120, além de conter disposições típicas de polícia judiciária, como a que se encontra no art. 10, §1ํㅜ "para a formação da culpa, nos crimes comuns, as mesmas autoridades policiais deverão, em seus distritos, proceder às diligências necessárias para descobrimento dos fatos criminosos e suas circunstâncias e transmitirão aos promotores públicos, com os autos de corpo de delito a indicação das testemunhas mais idôneas, todos os esclarecimentos coligidos; e desta remessa, ao mesmo tempo, darão parte à autoridade competente para a formação da culpa".

Regulando a aplicação da Lei oㅡㄹ 22.033, o Decreto no 4.824 de 1871, contudo, decida uma seção inteira à disposição do Inquérito Policial, que aparece pela primeira vez com esse nome na legislação processual penal brasileira, embora não o tenha criado, pois suas funções já há muito constavam em leis anteriores. Nesse Decreto, dispõe-se ainda sobre as atribuições dos chefes, 
delegados e subdelegados de polícia, entre as quais se encontram as diligências que deveriam proceder no caso de notícia de crime, bem como no caso de flagrante.

Após proclamada a República, quando cada Estado passou a ter competência para legislar em matéria processual, o Código de Processo do Distrito Federal, por exemplo, embora não disponha expressamente sobre a polícia judiciária, tratava em capítulo próprio "da investigação" sobre a atribuição da autoridade policial, dispondo que lhes competia "I- fornecer às autoridades judiciárias informações necessárias ao descobrimento dos autores e cúmplices de qualquer infração penal e verificação de sua identidade", bem como "II-auxiliar a instrução criminal, praticando com solicitude, as diligências requisitadas pelo juiz ou pelo Ministério Público" e "III-cumprir os mandados e requisições das autoridade competentes" (art. 244).

Voltando a ter Código de Processo Penal nacional, em 1943 o Decreto-Lei no 3.689 dispõe inicialmente que: “A polícia judiciária será exercida pelas autoridades policiais no território de suas respectivas jurisdições e terá por fim a apuração das infrações penais e da sua autoria" (art. $4^{\circ}$ ), cuja redação é modificada pela Lei no 9.043/1995, para trocar "jurisdições" por "circunscrições". Nesse ponto, a disciplina normativa da polícia judiciária já está sob uma concepção constitucional que a entende, em definitivo, como algo que, embora não se confundindo com a polícia da administração pública, também não se deve confundir com a jurisdição do poder judiciário.

\subsection{A POLÍ́CIA JUdiciáRia NA CONSTITUIÇÃo}

13. Antes da Constituição atual, em nenhuma outra se encontra qualquer referência à polícia judiciária. Apenas na Constituição de 1967 há, contudo, referência a possibilidade de habeas corpus 
no Tribunal Federal de recursos contra ato do responsável pela direção da Polícia Federal (art. 117, I, c).

A Constituição de 1988, no entanto, ao fazer referência expressa à polícia judiciária como função que se exerce pelas polícias civis e polícia federal, dispõe de forma que parece distinguir entre essa função e a de investigação criminal.

Em seu artigo 144, §1ํㅡㄹ dispõe ser competência da Polícia Federal, em seu inciso I, “apurar infrações penais contra a ordem política e social ou em detrimento de bens, serviços e interesses da União ou de suas entidades autárquicas e empresas públicas, assim como outras infrações cuja prática tenha repercussão interestadual ou internacional e exija repressão uniforme, segundo se dispuser em lei". Mas, no inciso IV, em separado, diz que lhe compete ainda "exercer, com exclusividade, as funções de polícia judiciária da União"

E no $\$ 4^{\circ}$, dispõe ainda que “às polícias civis, dirigidas por delegados de polícia de carreira, incumbem, ressalvada a competência da União, as funções de polícia judiciária e a apuração de infrações penais, exceto as militares".

Essa redação dissociativa tem gerado uma jurisprudência no Superior Tribunal de Justiça que vem entendendo serem possíveis atos de investigação praticados pela Polícia Militar, a exemplo do que se pode ler no HC 303494 SC 3014/0225286-6 (Rel. Ministro Sebastião Reis Júnior, DJ 17/06/2015), sustentando no pressuposto de uma doutrina tradicional que nulidades ocorridas na investigação não podem tornar nula a ação penal.

Em seu argumento, o acórdão recorre a outro julgado em que se afirma o seguinte: "A Constituição da República diferencia as funções de polícia judiciária e de polícia investigativa, sendo que apenas a primeira foi conferida com exclusividade à 
polícia federal e à polícia civil" (HC 256.118/SC, Ministra Maria Thereza de Assis Moura, DJ 9/6/2014).

Esses julgados instalam uma insegurança jurídica no processo penal sem precedentes. Para além de deduzir indevidamente que, por falta de exclusividade constitucional, permite-se a um outro órgão policial realizar investigação à revelia de lei formal que o autoriza, o julgado ignora não apenas uma tradição histórica nacional sobre o significado de polícia judiciária, como incorre em uma absoluta incompreensão da ideia de polícia judiciária na história das instituições processuais penais.

Não bastasse isso, o STJ ignora solenemente a Sentença de 6 de junho de 2009 da Corte Interamericana de Direitos Humanos (Caso Escher vs. Brasil), na qual ficou consolidado que a Polícia Militar não poderia ter realizado investigação criminal, com recurso a interceptação telefônica, mesmo com autorização judicial $^{44}$.

A jurisprudência tem ignorado o que há de problemático na confusão entre as funções de polícia o Estado de Direito e o que isso implica de desastroso ao devido processo. É precisamente a isso que se deve prestar um direito de polícia judiciária, a evidenciar o que há de especialmente relevante na ciência do direito em tema de polícia judiciária, buscando enfatizar seus problemas para que se levem a sérios certos princípios processuais penais que estão a depender de uma compreensão do órgão em comunhão com suas funções.

\subsection{AS CONCEPÇÕES DOUTRINÁRIAS}

14. A doutrina processualista penal nacional sempre entendeu que a polícia judiciária abrange precisamente a investigação cri-

44 Cf. em especial §136 da Sentença: http://www.corteidh.or.cr/docs/casos/articulos/ seriec_200_por.pdf. 
minal. Joaquim Canuto Mendes de Almeida observa que há dois critérios para distinguir a polícia judiciária da administrativa. Pelo primeiro critério, baseado e na distinção entre funções preventivas e funções repressivas, “a polícia judiciária opera depois das infrações para investigar a verdade e, a respeito, prestar informações à justiça". Pelo segundo critério, baseado na diferença de efeitos judiciais das funções policiais, "o valor de prova judicial assinala um ato judiciário da polícia, uma função de polícia judiciária", ao passo que a polícia administrativa alcança valor meramente informativo. Nesses termos, conclui que "Polícia Judiciária é, pois, em correlação oposta à polícia preventiva, a polícia repressiva, auxiliar do Poder Judiciário; e, em correlação oposta à polícia que auxilia por informações, a polícia que prepara provas judiciais" 45 .

Claro é que esse conceito se deve atualizar para falar não de auxiliar do Poder Judiciário, mas de "função essencial à Justiça", como se tem adequadamente defendido pela doutrina mais recente. E, sobretudo, deve-se ter em conta o valor condicionado da investigação à sua submissão ao contraditório. Mas a ideia central deve permanecer, pois retirar do conceito de polícia judiciária a função investigativa seria esvaziar seu sentido.

Apenas uma absoluta incompreensão do sentido histórico da polícia judiciária, não apenas no Brasil, mas sobretudo na história das instituições processuais penais desde França, permitir-nos-ia dissociar polícia judiciária de sua função investigativa. Apenas, colocando a polícia judiciária como órgão meramente auxiliar das funções judiciais, poder-se-ia fazer uma dissociação inconsequente. Mas, há muito tempo, a Polícia Judiciária no Brasil exerce suas atribuições como competência própria, não por delegação de uma qualquer autoridade judiciária. Os denominados "delegados de polícia" no direito brasileiro - embora man-

45 MENDES DE ALMEIDA, J. C. Princípios fundamentais do processo penal, 1973, p. 60. 
tenham a denominação histórica - não guardam mais qualquer resíduo de subordinação funcional, pois atuam segundo uma lógica de interdependência funcional que a Lei $n^{0}$ 12.830/2013 veio apenas reafirmar formalmente ${ }^{46}$.

Afinal, há muito tempo, já advertia Hélio Tornaghi que, “se organicamente a polícia judiciária entronca na máquina administrativa do Estado, funcionalmente ela se liga ao aparelho judiciário"; mas nisso não se pode ver qualquer subordinação do órgão a qualquer outra instituição. E por isso acresce que "não há nenhuma subordinação hierárquica, disciplinar, entre polícia judiciária e o Poder Judiciário ou mesmo o Ministério Público, mas apenas interdependência funcional" ${ }^{\prime 7}$. E é precisamente nessa fórmula - "interdependência funcional" - que se capta, pelo menos na história do processo penal brasileiro com seu modelo de investigação criminal, a ideia fundamental da polícia judiciária que o STJ tem ignorado e afundado numa interpretação canhestra da Constituição.

Em suma, “a principal atribuição da polícia judiciária é a de proceder a inquérito para apuração dos fatos criminosos e de sua autoria" 48 , e sem essa compreensão toda a arquitetura nacional de um devido processo penal pode desaguar numa insegurança jurídica da investigação criminal, em que, sem prévia atribuição de competência, um cidadão se pode ver investigado por qualquer órgão ou até por mais de um órgão, como vem acontecendo recentemente no Brasil.

É, portanto, cada vez mais urgente compreender que, embora se tenha colocado no capítulo da Segurança Pública, a Polícia Judiciária consiste em outra coisa destina. E essa é a con-

46 Cf. a respeito, nosso PEREIRA, E. S.; DEZAN, S. L. Investigação Criminal conduzida por Delegado de Polícia. Comentários à Lei 12.830/2013, Curitiba: Juruá, 2013.

47 TORNAGHI, H. Institiuções de Processo Penal, V. II, 1977, p. 202.

48 TORNAGHI, H. Institiuções de Processo Penal, V. II, 1977, p. 235. 
cepção que se vai desenvolver por José Pedro Zaccariotto, para quem houve uma acomodação constitucional inadequada da Polícia Judiciária. Para ele, a polícia judiciária se deve entender como função essencial à justiça, orientada precisamente à investigação criminal, como forma de garantir uma segurança pública integral $^{49}$.

É nessa linha que parece se apresentar uma proposta de Emenda Constitucional de Fábio Konder Comparato visando a transferir a Polícia Judiciária do capítulo "da segurança pública" para o capítulo "das funções essenciais à justiça", sobre o que Jacinto Nelson de Miranda Coutinho observa a necessidade de atribuir autonomia institucional e funcional à Polícia Judiciária, retirando-lhe o controle externo pelo Ministério Público para colocá-la sobre controle de um Conselho Nacional de Polícia Judiciária ${ }^{50}$.

A ideia de polícia judiciária, bem como o direito que se lhe segue, parece nos conduzir, assim, inevitavelmente, a uma questão de modelo de devido processo penal que queremos, pois vai implicar uma discussão sobre as relações de poder entre Polícia e Ministério Público, sobretudo relativamente a quem compete a direção do inquérito ${ }^{51}$. Mas, sobretudo, é uma questão que se deve compreender no quadro de uma história das instituições processuais penais em conformidade com a ideia de um Estado de direito.

49 ZACCARIOTTO, J. P. A polícia judiciária no Estado Democrático, 2005, p. 212ss.

50 Disponível em http://www.oab.org.br/editora/revista/users/ revista/1211292337174218181901.pdf.

51 Acerca dessa questão, cf. as posições e modelos de direito comparado: AMBOS, K. Control de la policía por el fiscal versus domínio policial de la instrucción, Proceso penal. Perspectiva internacional, comparada y latinoamericana, 2009, pp. 3-28; MATHEUS, E. "O Equilíbrio de Poder entre a Polícia e o Ministério Público", Processos Penais da Europa, 2005, pp. 481-506. 


\section{Considerações Finais}

\subsection{POLÍCIA JUdiCIÁRIA, FUNÇÃo E ÓRGÃo.}

15. Hélio Tornaghi sintetiza muito adequadamente a ideia de polícia judiciária na história das instituições processuais penais, ao observar que: "Não havia distinção nítida entre o juiz e a polícia judiciária. A partir do século XVI é que a doutrina e a legislação vão extremando as duas noções e os Estados vão instituindo uma polícia judiciária organizada. Já não apenas órgãos administrativos ou judiciários aos quais se cometem essas funções de modo mais ou menos confuso, ..., mas um corpo sistematizado e com essa destinação. Do século XVII em diante, pode considerarse adquirida a noção de polícia judiciária, perfeitamente distinta, quer dos outros tipos de polícia, quer do órgão judiciário" ${ }^{52}$.

A ideia geral de Polícia Judiciária que se contém na concepção de Faustin Helie, contudo, nos remete apenas a uma função. Essa é a primeira intuição histórica francesa que se vai colher pelo Brasil, onde se dá um passo a mais na sua determinação como órgão. Na terminologia de uma teoria das instituições, a noção de polícia judiciária no Brasil comporta tanto uma instituição-organismo, quanto uma instituição-mecanismo ${ }^{53}$.

O modelo brasileiro de polícia judiciária não se contenta apenas com sua concepção como "função essencial à justiça", mas antes e sobretudo como "órgão essencial à justiça". Mas é precisamente nesse ponto que a história está incompleta, pois mesmo no Brasil, onde houve uma afirmação histórica da polícia

52 TORNAGHI, H. Institiuções de Processo Penal, V. II, 1977, p. 200.

53 A teoria fundamental da instituição é de HAURIOU, M. A teoria da instituição e da fundação, 2009, embora Hauriou não tenha tratado das chamadas instituiçõesmecanismo, terminologia tipológica que se encontra em BERGEL, J.-L. Teoria geral do direito, 2001. 
judiciária como órgão, parece permanecer incompreendida por vacilações jurisprudências e por tentativas de excluir a polícia judiciária como órgão autônomo no processo penal, bem como de distribuí-la a diversos órgãos, segundo um modelo que parece querer retomar o que foi o CIC de 1808, em que o MPO era o agente supremo da polícia judiciária que estava sob sua orientação e dependência. Não é necessário grande esforço hermenêutico para compreender o que há de concentração de poder nesse modelo e o que ele pode representar às instituições processuais penais.

Essa ideia corresponde a uma específica concepção histórica de polícia judiciária que, conquanto tenha representado um avanço na história das instituições processuais penais, ainda permanece a meio do caminho. Ela permanece na ideia de que não precisa haver um órgão destacado, autônomo funcionalmente, bastando ter uma competência técnica, aperfeiçoada tecnologicamente, mas orientada por outro órgão - seja pelo juiz no modelo instrutório de investigação, seja pelo ministério Público no modelo acusatório que se tem afirmado na Europa continental. E é contra isso que o modelo brasileiro se insurge.

16. O modelo brasileiro de investigação criminal - que se estabelece na relação entre delegado de polícia e inquérito policial - acresce à ideia de polícia judiciária algo que tem sido negligenciado pelos sistemas processuais, que é a tentativa de manter não apenas o órgão julgador distante da fase de investigação do processo, em defesa da liberdade processual, mas também o órgão de acusação, em defesa de uma igualdade processual, tendo assim em vistas uma verdade processual duplamente limitada por outros dois órgãos do poder punitivo. Esse modelo, ademais, em vindo a ser aperfeiçoado, pode permitir uma integração da defensoria pública como contra-poder da acusação ${ }^{54}$, asseguran-

54 Essa é uma hipótese que tem sustentado AMBOS, K. Principios del processo penal europeo. Análisis de la Convención Europea de Derechos Humanos, 2005, p. 124. 
do a realização de uma igualdade processual desde a primeira fase do processo penal.

Nessa concepção, a Polícia Judiciária afirma-se, assim, não apenas como função, mas como órgão essencial à justiça penal. Trata-se, em última análise, de compreender que a questão da polícia judiciária é uma questão de divisão do poder punitivo, que se deve compreender em continuidade do princípio acusatório - que divide acusação e julgamento - para avançar com uma outra divisão entre acusação e investigação, visando a evitar um inquérito que seja unidirecional como por muito tempo se tem erroneamente sustentado pela doutrina processual construída por membros do Ministério Público.

É, portanto, como questão de divisão do poder punitivo, na sequência de uma divisão mais geral do poder, que se deve compreender a ideia geral de uma Polícia Judiciária. Por isso, Luigi Ferrajoli, muito adequadamente, observa que:

Na lógica do Estado de direito, as funções de polícia deveriam ser limitadas a apenas três atividades: a atividade investigativa, com respeito aos crimes e aos ilícitos administrativos, a atividade de prevenção de uns e de outros, e aquelas executivas e auxiliares da jurisdição e da administração. Nenhuma destas atividades deveria comportar o exercício de poderes autônomos sobre as liberdades civis e sobre os outros direitos fundamentais. As diversas atribuições, por fim, deveriam estar destinadas a corpos de polícia separados entre eles e organizados de forma independente não ape ᄀnas funcional, mas também, hierárquica e administrativamente dos diversos poderes aos quais auxiliam ${ }^{55}$.

E, para que não subsistam dúvidas, Ferrajoli afirma muito expressamente que: "Em particular, a polícia judiciária, destinada à investigação dos crimes e a execução dos provimentos jurisdicionais, deveria ser separada rigidamente dos outros corpos de polícia e dotada,

55 FERRAJOLI, L. Direito e razão. Teoria do garantismo penal, 2002, p. 617. 
em relação ao Executivo, das mesmas garantias de independência que são asseguradas ao Poder Judiciário do qual deveria, exclusivamente, depender" ${ }^{\prime \prime}$. E é com essa chave de compreensão da ideia de polícia judiciária que devemos constituir um direito de polícia judiciária.

\subsection{DIREITO DE POLÍCIA JUDICIÁRIA, ZETÉTICA E DOGMÁTICA}

17. A compreensão da ideia de polícia judiciária se deve remeter ao processo penal de um Estado de Direito em garantia de direitos fundamentais. $\mathrm{O}$ Estado de direito, contudo, exige-nos não apenas a divisão do poder, mas também uma proporcionalidade de ação, como limites ao exercício do poder ${ }^{57}$. Claro é que se pode objetar não haver qualquer direito a uma específica organização do poder e a um específico procedimento de investigação, o que nos deveria remeter não a um direito de polícia judiciária, mas a uma questão de política constitucional. Mas não se pode considerar o direito apenas dogmaticamente, como interpretação positivista do direito posto, se tivermos em conta que também uma perspectiva zetética é possível à ciência do direito ${ }^{58}$.

Há, ademais, que se considerar, da perspectiva dos direitos fundamentais implicados no processo penal, a possibilidade de discutir a questão de um direito a organização e procedimento. Robert Alexy defende a existência de direitos a organização e procedimento como direitos subjetivos com status positivo ${ }^{59}$. Ele considera que se trata de um direito que se pode opor ao legislador. Embora exista uma densa discussão sobre seu status positivo ou negativo, bem como sua natureza objetiva ou subje-

\footnotetext{
56 Idem, ibdem (com itálico nosso).

57 Cf. GOSSEL, K.-H. El derecho procesal penal en el Estado de derecho, 2007, pp. 23-25.

58 Cf. FERRAZ JR, T. Introdução ao estudo do direito, 2007, p. 39ss, a respeito dos diferentes enfoques teóricos da ciência jurídica.

59 ALEXY, R. Teoria dos direitos fundamentais, 2011, p. 470ss.
} 
tiva, Alexy sustenta que não se pode ignorar a existência de uma relação de dependência entre garantia dos direitos fundamentais e existência de uma certa organização e procedimento ${ }^{60}$.

Nessa perspectiva, portanto, podem-se suscitar todas as questões que concernem à ideia de polícia judiciária no quadro dos problemas processuais que concernem aos direitos fundamentais, para discutir uma determinada organização do poder punitivo e do procedimento com que ele atua.

18. A ideia de Polícia Judiciária, portanto, encarna tanto uma questão de organização do poder punitivo - orientada por princípio de divisão do poder, não apenas da justiça e da polícia, mas dessa em administrativa e judiciária - como também uma questão de procedimento do poder punitivo - orientado por princípio de proporcionalidade no desenvolvimento do processo desde a sua fase preliminar de investigação criminal. A Polícia Judiciária, nesse sentido, entende-se não apenas como uma função que se manifesta na atividade de investigação criminal, segundo o princípio da proporcionalidade, mas antes como um órgão do Estado de Direito orientado pelo princípio da divisão do poder. Ela se insere no equilíbrio necessário dos diversos sujeitos processuais segundo uma arquitetura que pretende alcançar um devido processo penal.

Esse é, certamente, o modelo brasileiro de polícia judiciária que, conquanto seja periférico relativamente a modelos estrangeiros tradicionais (em especial, o europeu continental e o inglês), acaba por ser um modelo específico que congrega elementos importantes de cada um, a merecer um direito de polícia judiciária como disciplina que possa evidenciar o que há de particularmente novo e especialmente importante à efetiva concretização de um devido processo penal.

60 Trata-se do que chama de fórmula cunhada por Konrad Hesse, para quem "organização ou procedimento [revelam-se] com frequência o - provavelmente único - meio de se produzir um resultado conforme aos direitos fundamentais". 
É nesse sentido, portanto, que se deve desenvolver um direito de polícia judiciária no Brasil, como espaço disciplinar da ciência jurídica em que se levem a sério os direitos fundamentais processuais desde a fase preliminar de investigação criminal, permitindo à polícia judiciária compreender-se como sujeito processual relevante à sua efetividade.

\section{ReFERÊnCIAS Bibliográficas}

ALESSI, G. Il processo penale. Profilo storico. Roma-Bari: Laterzz, 2011

ALEXY, R. Teoria dos direitos fundamentais. São Paulo: Malheiros, 2011.

ALMEIDA JR, J. M. Processo criminal brasileiro I, Rio de Janeiro: Typ. Batista de Souza, 1920.

AMBOS, K. Control de la policía por el fiscal versus domínio policial de la instrucción, Proceso penal. Perspectiva internacional, comparada y latinoamericana, 2009, México: UBIJUS, pp. 3-28.

AMBOS, K. Principios del proceso penal europeo. Análisis de la Convención Europea de Derechos Humanos. Bogotá: Universidad Externado de Comlombia, 2005.

BERGEL, J.-L. Teoria geral do direito. São Paulo: Martins Fontes, 2001.

FAUTIN HELIE, M. Traite de l'instruction criminelle, Tomo III. De la police judiciaire. Paris: Henri Plon, 1866 (disponivel em Gallica - Bibliothèque Nationale de France: http://gallica.bnf.fr)

FERRAJOLI, L. Direito e razão. Teoria do garantismo penal. São Paulo: RT, 2002.

FERRAZ JR, T. Introdução ao estudo do direito. São Paulo: Atlas, 2007. 
GARRAUD, R. Compendio de direito criminal, Lisboa: Liv. Classica, 1915.

GOENAGA, M. Lecciones de derecho de policía, Bogotá: Temis, 1983.

GOSSEL, K.-H. El derecho procesal penal en el Estado de derecho. Obras completas. Tomo I. Santa Fé: Rubinzal-Culzoni, 2007.

GUEDES VALENTE, M. M. Teoria Geral do Direito de Policial, Coimbra: Almedina, 2014

HAURIOU, M. A teoria da instituição e da fundação. Porto Alegre: Safe, 2009

INGLETTI, V. Diritto di polizia giudiziaria, Roma: Laurus Robuffo, 2015.

LLERAS PIZARRO, M. Derecho de Policía, Colombia: Diké, 2009.

MARQUES, J. F. Elementos de direito processual penal, V. I. Campinas: Millenium, 2000.

MATHEUS, E. “O Equilíbrio de Poder entre a Polícia e o Ministério Público", Processos Penais da Europa, 2005, Rio de Janeiro: Lumen Juris, pp. 481-506.

MENDES DE ALMEIDA, J. C. Princípios fundamentais do processo penal, São Paulo: RT, 1973.

MINGUIJÓN ADRIÁN, S. Historia del derecho español I. Barcelona: Labor, 1927

MORAES, B. B. Direito e Polícia. Uma introdução à Polícia Judiciária. São Paulo: RT, 1983.

PARKER, N. As revoluções e a história. Lisboa: Temas e Debates. 2001

PEREIRA, E. S.; DEZAN, S. L. Investigação Criminal conduzida por Delegado de Polícia. Comentários à Lei 12.830/2013, Curitiba: Juruá, 2013. 
SALAZAR CULI, F. Derecho de Policía. Polícia administrativa. Barcelona-Buenos Aires: Salvat Editores, 1942.

SANTALUCIA, B. Diritto e processo penale nell'antica Roma, Milano: Giuffrè, 1998.

TAMBURRO, G. Il diritto di polizia. La polizia amministrativa e la polizia di sicurezza nella legislazione fascista. Roma: Sormani, 1938.

TONINI, P. Polizia Giudiziaria e Magistratura. Milano, Giuffrè, 1979

TORNAGHI, H. Instituições de Processo Penal II, São Paulo: Saraiva, 1977

TOURINHO FILHO, F. C. Processo Penal 1. São Paulo: Saraiva, 2002.

TUCCI, R. L. Lineamentos de processo penal romano. São Paulo: Editora USP, 1976

VOVELLE, M. A Revolução Francesa (1789-1799). Coimbra: Edições70, 2007.

ZACARIOTTO, J. P. A polícia judiciária no Estado democrático, Sorocaba (SP): Brazilian Books, 2005. 